\title{
Guest Editorial: ENERGETICALLY AND ECOLOGICALLY SUSTAINABLE, AFFORDABLE AND HEALTHY BUILT ENVIRONMENT
}

\author{
Irene LILL ${ }^{1, *}$ \\ ${ }^{1}$ Building Lifecycle Research Group, Department of Civil Engineering and Architecture, School of Engineering, \\ Tallinn University of Technology, Ehitajate tee 5, 19086 Tallinn, Estonia
}

European citizens spend over $90 \%$ of their time in buildings, which causes increase of energy consumption but also health and comfort complaints. Energetically and ecologically sustainable, affordable and healthy built environment concept has received remarkable attention for tackling various problems, as: meeting technical, technological, economic and health requirements, but also quality of life, biophysical, political, social, cultural, ethical, psychological, emotional, religious and ethnic aspects.

Practitioners use integrated data captured from micro-, meso- and macro levels and therefore the big data and text analytics approach usually leads to multidisciplinary theoretical problem solving. The operation and maintenance of sustainable, affordable and healthy built environment systems are undergoing noticeable transformation because of huge amount of data and knowledge provided by rapidly emerging testing and monitoring systems.

This special issue strives to review the development and key applications of new tools and methods in this area. It can serve as a valid reference for a successful application of new tools and methods challenging balanced and sustainable built environment.

In the first two papers, Lithuanian and Belarus researchers achieve the synergy of joint effort. Tupenaite and co-authors took a research on apartment building performance for refurbishment purposes. This is a good example how the multiple criteria method, developed in the Vilnius Gediminas Technical University, has spread worldwide and is applicable in other countries and situations. Their methodology enables an integrated assessment of apartment buildings' performance, the selection of the worst performing buildings and appropriate measures for their refurbishment, but also an estimation of potential results. The presented case study, illustrated the proposed methodology in use, with five apartment buildings as al- ternatives. Sensitivity analysis revealed that assessments were accurate enough for further applications. Authors suggest refurbishment measures for the worst performing buildings and figure that in general, it is possible to reduce energy consumption of these buildings by more than $60 \%$ and GHG emissions by over $50 \%$.

Trinkunas and co-authors present a decision support model and recommendations about sustainable development of real estate that could help Lithuania during economic crises. They suggest that successful construction and real estate crisis management strategy should take into consideration economic, social, demographical, political, technological, environmental, psychological and other factors of the country. Decision support model, proposed by the authors, includes extensive analysis of global trends, best crisis management practices, factual situation and provision of recommendations for different stakeholders at macro-, meso- and micro- levels under conditions of market instability. The model tested on Lithuanian case study is also applicable for other transitional economies.

Authors from United Kingdom draw attention that a sustainable urban environment will not lead to improved disaster resilience; it should also cater for peoples' needs and expectations. It is possible to attract more investors and increase the property value by meeting the needs of people. Designing a disaster resilient and user focused urban environment is not an easy task. Dias and co-authors argue that the current top-down urban design process does not cater sufficiently for the user needs and hence fail to create sustainable urban environments. In a bid to address this issue, they propose a bottom up urban design process. In order to establish the critical success factors for this bottom up approach, the authors have conducted 35 in depth semi-structured interviews with 35 community

*Corresponding author. E-mail: irene.lill@ttu.ee 
members and 12 community leaders. They have identified six critical success factors in their study and discussed the impact of these critical success factors on implementing a user centric, bottom up urban design process.

Researchers from University of Huddersfield and University of Salford indicate in their joint paper that nonuser centric urban design approaches not only alienate user requirements, but often they fail to see how an urban space (especially streets) could effectively be shared between pedestrians and vehicles. Often in orthodox urban street designs, the spaces favour vehicular traffic over pedestrian use. Jayakody and co-authors discuss the concept of Shared Space Street (SSS) design in a bid to encourage pedestrian friendly urban street designs. By evaluating three case studies, they establish four main objectives that SSS processes should follow to make successful Shared Space Streets in urban environments.

The last paper by Italian researchers Tampieri and Canonico discusses a network-analysis approach to the performance control of integrated built-environment systems based on efficiency, effectiveness, and adequacy. They apply this perspective to the network systems of local transport companies. They examine empirically a pilot case of local public transport companies, test the adequacy of network and give evidence for the optimal localization of governance among units providing the transport services. Retrieved results support the hypothesis that, although structural centralization was ostensibly oriented towards increasing governance, the structure actually devolved into decentralized control at the periphery of the network, diminish the effectiveness of initiatives. Furthermore, the multidimensional analysis grid allows understanding the appropriate way to structure networks and to maintain effective governance in complex systems by considering the span of control as a concept leading to a balance between first- and second-order ties.

Finally, the papers in this issue present also the deliverables of EU funded international program Tempus project CENEAST: Reformation of the Curricula on Built Environment in the Eastern Neighbouring Area (530603-TEMPUS-1-2012-1-LT-TEMPUS-JPCR), which involved 14 partners from Lithuania, Estonia, Italy, UK, Belarus, Russian Federation and Ukraine. CENEAST project aimed to develop a virtual interuniversity network and to transfer the Bologna practices into educational system of Belarussian, Russian and Ukrainian universities and upgrade their curricula on built environment in order to increase their capacity, to modernise the quality and relevance of education of the building and civil engineering students to the labour market needs. 